\title{
The ethical concerns of physician recruitment from Africa to the global North
}

\author{
Ann Marie Corrado \\ Faculty Reviewer: Ken Kirkwood, PhD (School of Health Studies)
}

\begin{abstract}
For decades, medical recruitment agencies have tried to deal with physician shortages in rural and remote areas of developed countries by recruiting physicians from areas of scarce health human resources in the global South. In South Africa alone, one-third to one-half of medical school graduates migrate to the global North every year, with the majority settling down in Canada, the United States, and the United Kingdom. ${ }^{1}$ This review paper aims to bring attention to the unethical practice of physician recruitment from Africa to the global North. In particular, it will explore how physician recruitment negatively impacts the donor countries' economies, compromises the quality of care they can give their citizens, and provides only a short term solution to the recipient country. It is critical that this practice is prohibited and that countries in the global North look for sustainable solutions within their own borders to solve workforce shortages.
\end{abstract}

\section{INTRODUCTION}

Many foreign medical graduates choose to move to developed countries due to push factors, such as unsafe living conditions and famine, which cause people to want to move voluntarily. ${ }^{2}$ Ethically, the principle of respect for autonomy supports the idea that individuals have the right to make choices freely and, therefore, they should move if they desire. ${ }^{3}$ The ethical problem arises when physician-recruiting agencies capitalize on pull factors, which are circumstances in the destination countries, such as better remuneration and career opportunities, ${ }^{2}$ that are emphasized to entice physicians and motivate them to migrate. ${ }^{4}$ From an ethical point of view, this "selective and targeted 'raiding' of developing countries' medical workforce by wealthier countries is not acceptable". 5

In the 1990s, rural and remote regions in Canada experienced severe physician shortages ${ }^{6}$ since Canadian-trained physicians often avoid locating their practices in these communities. As a result, Canada began looking abroad for foreign-trained physicians who would be willing to practice in these areas. ${ }^{6}$ The recruitment efforts by Canadian provinces have resulted in 60 South African physicians migrating each year since the $1990 \mathrm{~s}^{6}$ and primarily settling down in the Canadian prairies. ${ }^{7}$ These foreign doctors are able to bypass the normal barriers to accreditation and get their full license as long as they work in the assigned community for 3-5 years through a Return of Service agreement. ${ }^{7}$ In the coming years, it is expected that physician recruitment from Africa will continue as an aging population, coupled with changes in physician demographics (specifically age and gender) in developed nations, will result in doctors working fewer hours, and therefore, increasing the need for foreign doctors. ${ }^{6}$

The World Health Organization (WHO) has recently stated that, "the world faces a global shortage of over 4.3 million doctors, nurses, and other healthcare professionals". ${ }^{2}$ This lack of health human resources is one of the most urgent global health issues of our time, with the greatest burden being in developing countries. ${ }^{2} \mathrm{Al}$ though Canada and other developed countries actively recruit more physicians from India and the Philippines, the proportion of African-trained physicians is the highest. ${ }^{8}$ Moreover, any government that recognizes that their country has a large number of physicians, such as the Philippines, encourages those doctors to work in the global North to gain clinical skills, whereas governments in Africa, such as Kenya's, do not encourage migration to the global North as they have extensive unmet health care needs. ${ }^{9}$

\section{IMPACT ON THE DONOR COUNTRY'S ECONOMY}

Countries in Africa with scarce economic resources invest a significant amount of money into their medical students in order to provide them with free education. ${ }^{10}$ The justification for these states subsidizing the cost of medical education is to ensure that they are investing enough into the production of human capital, who will later serve the needs of their populations. ${ }^{7}$ When physicians are recruited to leave their country of origin, it results in a substantial economic loss to the country. ${ }^{1}$ For example, each time a doctor migrates from Kenya to the global North, it creates a pure economic loss of $\$ 517,931$ to the economy. ${ }^{1}$ This loss of human capital is problematic as it violates the principle of distributive justice, which requires the fair distribution of scares resources among all persons in society. ${ }^{3}$ Moreover, the principle of justice also requires that "each and every member of the community should receive an equal share of the benefits and burdens of the cooperative venture". ${ }^{11}$ Physician recruitment is therefore unjust as it ignores the rights of patients in Africa, themselves taxpayers, who cannot benefit from the knowledge and skills that physicians have obtained with the state's financial assistance. ${ }^{12}$

Researchers have stated that the only individuals that benefit financially from the migration pipeline from Africa to the global North are the physicians who will earn higher salaries and patients in the recipient country. ${ }^{11}$ Currently, is no requirement for countries in the global North, such as those in Canada and the United States, to compensate the African countries from which they have recruited physicians. ${ }^{10}$ As recipient countries' economies are stimulated, they are able to solve their own labour shortages in rural areas, and they save money by not having to train these health professionals. ${ }^{11}$ 
Critics have challenged the ethical concerns relating to the economic losses in African countries by asserting that these physicians will send money back home to their families. ${ }^{4}$ However, when considering the principle of non-maleficence, which supports that a procedure should not harm a patient or society, ${ }^{3}$ it is evident that physician recruitment is not ethical. Available evidence suggests that the harm done to the system is so significant that, even if doctors earn more in the receiving country and send money home, they cannot compensate for the damaging effects on the local health care system. ${ }^{4}$

\section{COMPROMISED QUALITY OF CARE}

The quality of care patients receive is also impacted by shortages in staff, which leave existing staff with excessive workloads. ${ }^{13} \mathrm{Al}-$ though the care patients receive is affected by the number of health personnel regardless of their country of origin, it is more concerning in Africa as Africans make up $10 \%$ of the world's population but "bear $25 \%$ of the global burden of disease". ${ }^{2}$ A lack of physicians results in patients receiving shorter appointments and doctors feeling stressed when attempting to meet the needs of those patients. ${ }^{12}$ On average, patients are only given 1-5 minutes for their first clinical encounter with the doctor and even shorter interactions at later appointments. ${ }^{12}$ These rushed meetings are problematic as they have been linked to more errors in diagnosis and treatment ${ }^{12}$ and as a result many patients die. ${ }^{3}$ When physicians are recruited by agencies in the global North, the principle of consequentialism, which is the view that the morally right action is the one that will have the best overall consequences, is violated. ${ }^{14}$ The specific consequence that results is the widening of health inequities between countries as citizens in Africa have a harder time accessing high quality, patient-centered care from physicians.

A counter argument to physician recruitment has been that doctors will one day return to Africa, with advanced skills and knowledge ${ }^{11}$ enhancing the quality of care they provide to patients. However, the WHO has claimed that the number of physicians who return is very small and in any year the net emigration of healthcare professionals, such as doctors, is much higher than the net immigration. ${ }^{11}$ In addition, when doctors do return, healthcare systems may not be able to utilize the skills doctors have gained because the technologies and heath infrastructure in Africa is much less advanced than those in the global north. ${ }^{4}$

\section{LACK OF LONG-TERM BENEFITS}

The benefits of physician recruitment to developed nations, such as Canada, have been described as ambiguous because physician recruitment from the global South provides only a short-term solution for rural and remote areas. ${ }^{7}$ After doctors obtain their full licenses and finish their Return of Service agreements, the majority move to urban centres in other provinces. ${ }^{7}$ This movement to larger cities, predominately in British Columbia and Ontario, demonstrates that recruiting doctors from Africa does not solve the workforce crisis in the developed world. ${ }^{7}$ Instead, this practice creates global disparities in health as it first shifts physician shortages to
African countries that are the least suited to cope with a limited number of doctors due to the high burden of diseases. ${ }^{2}$ Moreover, from a utilitarian point of view, recruitment is not ethical. Utilitarianism is the ethical doctrine that finds the right action to be the one that promotes "the greatest over-all or average happiness". ${ }^{15}$ This ethical framework makes it evident that physician recruitment should not be practiced as it deprives many people in Africa from accessing healthcare, in order to help rural areas in the global North for only a short period of time.

\section{CONCLUSION}

Although recruitment from Africa may be practiced with the intention of helping rural and remote areas of developed countries, it causes a significant amount of harm to the African economy and affects the quality of care that African citizens receive. Physician recruitment is problematic as it detrimentally impacts health systems as well as patient health, for only a short-term benefit in the recipient country. It is therefore imperative that this practice is stopped to ensure more equity in healthcare, so that all individuals can access good quality care regardless of their location. Countries in the global North must look within their own borders for sustainable solutions and create policies to support the retention of their own physicians in rural and remote areas.

\section{REFERENCES}

1. Huish R. How Cuba's Latin American School of medicine challenges the ethics of physician migration. Soc Sci Med. 2009 Aug;69(3): 301304.

2. Aluttis C, Bishaw T, Frank MW. The workforce for health in a globalized context - global shortages and international migration. Glob Health Act. 2014 Jan; 7: 1-10.

3. Gillon R. Medical Ethics: Four principles plus attention to scope. Brit Med J. 1994 Jul16;309(6948): 184-188.

4. Clarke PF, Stewart JB, Clark DA. The globalization of the labour market for health-care professionals. Int Labour Rev. 2006 Mar;145(1): 37-64.

5. Dauphinee WD. Physician Migration to and from Canada: the challenge of finding the ethical and political balance between the individual's right to mobility and recruitment to underserved communities. J Contin Educ Health Prof. 2005 Apr;25: 22-29.

6. Wright D, Flis N, Gupta M. The 'brain drain' of physicians: historical antecedents to an ethical debate. Philos Ethics Humanit Med. 2008 Nov;3(4): 1-8.

7. Grant HM. (2006). From the Transvaal to the Prairies: the migration of South African physicians to Canada. J Ethn Migr Stud. 2006 Aug;32(4): 681-695.

8. Hagopian A, Ofosu A, Fatusi A, et al. The flight of physicians from West Africa: views from West African physicians and implications for policy. Soc Sci Med. 2005 Oct;61(8):1750-60.

9. Kirigia J, Gbary AR, Muthuri LK, Nyoni J, Seddoh A. The cost professionals' brain drain Kenya. BMC Health Serv Res, 2006 Jul 17;6(89): $1-10$.

10. Astor A, Akhtar T, Matallana A, et al. Physician migration: views from professionals in Colombia, Nigeria, India, Pakistan, and the Philippines. Soc Sci Med. (2005) Dec;61(12): 2492-500.

11. Hooper CR. Adding insult to injury: the healthcare brain drain. J Med Ethics. 2008 Oct;24(9): 684-7.

12. Aluwihare, APR. Physician migration: donor country impact. J Contin Educ Health Prof. 2005 Feb;25(1): 15-21.

13. Chickanda, A. Skilled health professionals' migration and its impact on health delivery in Zimbabwe. J Ethn Migr Stud. 2006 Aug;32(4) 667-680.

14. Hurley P. Beyond consequentialism. New York: Oxford University Press; 2009.

15. Philips DC. Encyclopedia of educational theory and philosophy. Los Angeles: Sage; 2014. 